\title{
THE USE OF ELECTRONIC CIGARETTES - A NEW EPIDEMIC AMONG ROMANIAN CHILDREN AND TEENAGERS
}

\author{
Remus Gaga, Tudor Lucian Pop, \\ Pediatrics 2 Department, "Mother and child" Department, \\ „Iuliu Hațieganu” University of Medicine and Pharmacy Cluj-Napoca
}

\begin{abstract}
The use of electronic cigarettes or vaping is an increasingly popular habit among the youths around the world. The intense promotion of vaping devices, their use as a surrogate for classical cigarettes by those who wish to give up the bad habit, and teenagers' natural curiosity have turned electronic cigarettes into a new public health problem. The aim of this article is to present the vaping devices in an objective way, focusing on containing substances and their impact on health. We believe that the epidemic caused by this new trend can be stopped or at least slowed down by getting the correct information from sources of expertise, and by the joint efforts of parents, teachers, doctors and youths in Romania. Paediatricians, school doctors and psychologists need to sound the alarm and take preventive action in order to raise the awareness on the risks, and in order to limit the spread of vaping in our country.
\end{abstract}

Key words: vaping; electronic cigarettes/ e-cigarettes, epidemic, public health, children, teenagers.

\section{What are electronic cigarettes?}

Electronic cigarettes are devices that heat various substances in order to produce vapours. Once formed, the vapours contain tiny particles, called aerosols, that are inhaled by the consumers. The fundamental difference between electronic cigarettes and the classical ones is in the way aerosols are produced. Classical cigarettes contain tobacco, which, through combustion, release different substances that are then inhaled: polycyclic aromatic hydrocarbon (benzopyrene), tobacco-specific nitrosamine (nitrosonornicotine - NNN and 4-(methylnitrosamino)-1-(3-pyridyl)-1-butanone - NNK), aldehyde (acrolein, formaldehyde), Carbon monoxide, Hydrogen cyanide, Nitrogen Oxides, benzene, toluene, phenols (phenol, cresol) and aromatic amines (nicotine, 4-aminobyphenil - ABP) [1]. On the other hand, electronic cigarettes use the evaporation of the liquid as a means to produce aerosols.

At first sight, the evaporation mechanism has less pathological effects, and the substances resulted from the burning of tobacco are replaced with a healthier alternative. However, in reality, the liquid contained in the electronic cigarettes has nicotine, polyethylenglicol, glycerine and other harmful substances. This is how electronic cigarettes create addiction. Studies show that there are traces of nicotine also in the products advertised as safe from addiction, which could have been induced among children [2].

Also, electronic cigarettes contain polycyclic aromatic hydrocarbons, polyethylenglicol and glycerine. These can cause inflammation of pulmonary alveoli and airways. Experimental studies on lab animals show an increase of pro-inflammatory cytokines and imbalance of the oxidation-reduction mechanisms as a result of exposure to the vapours from electronic cigarettes [3-6]. There are also descriptions of the effect on the respiratory epithelium, on the pulmonary function, on the mucociliary clearance and on the pulmonary histology.

* Author correspondent: Tudor Lucian Pop, Pediatrics 2 Department, “Mother and child” Department, „Iuliu Hațieganu” University of Medicine and Pharmacy Cluj-Napoca, email: tudorlpop@yahoo.com

Article received: 27.10 .2021 , accepted: 23.11 .2021 , published: 15.12 .2021

Cite: Gaga R, Pop TL. The use of electronic cigarettes - a new epidemic among romanian children and teenagers. The Journal of School and University Medicine. 2021;VIII(4):50-53 
These data have also been confirmed by studies on the human pulmonary tissue, which have shown an increased level of inflammation and an increase of the expression of ACE2 receptors (the angiotensin-conversing enzyme 2), presenting the potential for harmful effect in the case of a SARS-CoV-2 virus infection in those who use e-cigarettes $[5,6]$. The mechanism by which the COVID-19 coronavirus uses ACE2 receptors as entry gate into the body is well known. We, therefore, are witnessing an overlapping of negative factors that the two epidemics (one caused by the COVID-19, and one caused by the use of electronic cigarettes) can have on the health of the youths in Romania. As such, the SARS-CoV-2 infection has lead not only to delaying the active and strong social campaign against vaping in our country, but also to emphasising the negative physio-pathological effects caused by vaping.

\section{Types of devices}

There are various vaping products, classified based on several features:

1) Pod-type modifiable devices allow the user to programme the battery tension of the device's power, as well as other things.

2) Pen-type devices, or those similar to a second-degree pod, are rechargeable and have an activating button.
3) Ciga-like rechargeable devices have the same mechanism as the previous ones, but they look like a classical cigarette.

4) Single-use ciga-like devices are not meant to be refilled or recharges, and are disposed of after use.

A recent study has shown that more than half of the youth interviewed prefer modifiable devices instead of the pen-type ones or instead of ciga-like devices [7].

\section{Are electronic cigarettes so popular among the youths?}

Between 2011 and 2015, the studies in the United States showed an increased in the use of e-cigarettes from $1,5 \%$ to $16 \%$ among high school students. The percentage reached $20,8 \%$ in 2018 [8]. Several studies confirm an alarming increase of vaping among Western European countries, and globally $[9,10]$. Also, studies now describe the cases of pulmonary distress associated with the use of e-cigarettes in Europe, too [11].

Globally, the data suggested in various questionnaires show an increased prevalence in the use of e-cigarettes, and the term epidemic described by some is a proper to the current situation (Figure 1) [12-14].

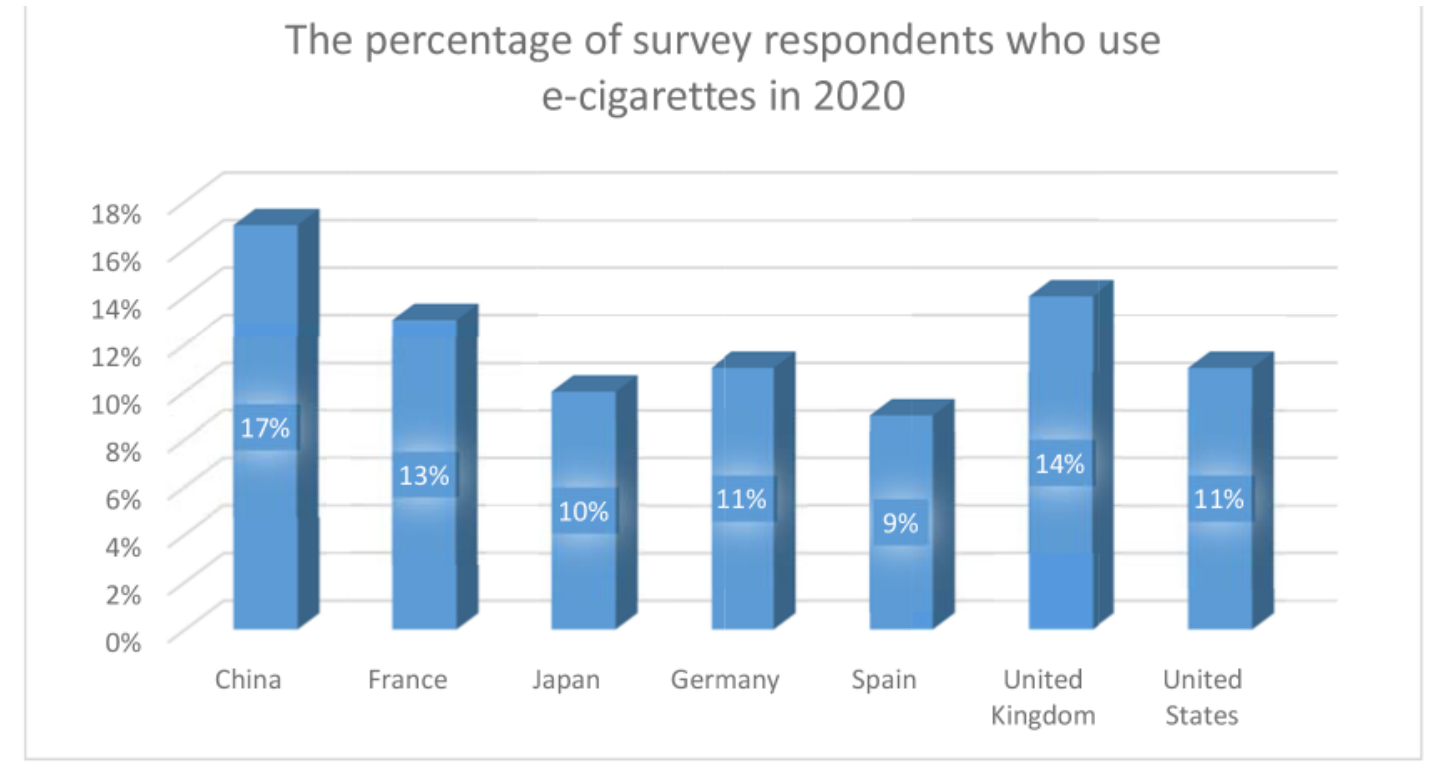

Figure 1 . The percentage of survey respondents who use e-cigarettes in 2020, by country. There have been 1000-4000 respondents in each country where the survey was applied (source: The Global Consumer Survey) [14]. 


\section{Disorders associated with the use of e-cigarettes}

Aside from the pro-inflammatory effect, affecting the pulmonary function, and the danger of associating vaping with COVID-19, as mentioned in the first paragraph, the pathology associated with the use of e-cigarettes is ever more varied, new physio-pathological associations are currently being found.

One of the most frequent conditions associated with conventional smoking is bronchial-pulmonary cancer. The malign risk does not seem to disappear in new smokers, however. The e-cigarette devices and the fluids in the vaping devices demonstrably contain a series of oncogenic substances, some of which have an indisputable effect, including nicotine derivate (e.g., nitrosonornicotine, ketone nitrosamine), polycyclic aromatic hydrocarbons, heavy metals (including organometallic compounds) and aldehydes / other complex organic compounds. These substances appear both as constituents of the e-liquid (with many aldehydes and other complex organic substances used as aromas), as well as resulting from pyrolisia / complex organic reactions with the e-cigarette device [15].

Other experimental studies ran on lab animals exposed to vapours from e-cigarettes have shown the association with malign conditions, such as pulmonary adenocarcinoma and urothelial hyperplasia of the gallbladder [16].

Also, there are isolated cases of squamous cell carcinoma (SCC) of the oral cavity, resulted from the use of e-cigarettes. The risk factors for developing SCC include infection of the human papillomavirus (HPV), use of tobacco and use of alcohol. HPVnegative squamous cell carcinoma is the most popular among elderly patients with a history of use of alcohol and tobacco. Nevertheless, a study in the United States described the case of a young adult who was using e-cigarettes and who was diagnosed with HPVnegative SCC, and who, unfortunately, had a rapid progressive and fatal evolution [17].

\section{How can this pandemic be stopped?}

A 2019 study analysed the smokers' decision to replace classic cigarettes with e-cigarettes. The important factors in the decision-making process was the perception of risks and benefits associated to the use of e-cigarettes as opposed to the use of classic ones, the social tendency to keep up with the use of e-cigarettes and the trust in the information offered [18].

Therefore, firstly, we need to acknowledge the dangers of using e-cigarettes at a society level. The implementation of social projects and public health actions promoted on online social media, TV and media, as well as the involvement of NGOs that include parents, students, teachers - all of this can decrease the effect of this pandemic among the youths of our country [19]. Also, general physicians together with paediatricians, school doctors and psychologists need to sound the alarm within their area of social interaction. It's time medicine in Romania focus more on aspects of prevention, and paediatricians approach a family-centred direction, with emphasis on the social implications of conditions on patients [20].

\section{Reference}

1. Omare MO, Kibet JK, Cherutoi JK, Kengara FO. A review of tobacco abuse and its epidemiological consequences [published online ahead of print, 2021 Jan 6]. Z Gesundh Wiss. 2021;1-16. doi:10.1007/s10389-020-01443-4

2. Münzel T, Hahad O, Kuntic M, Keaney JF, Deanfield JE, Daiber A

Eur Heart J. 2020 Nov 1; 41(41):4057-4070.

3. Lerner CA, Sundar IK, Yao H, et al. Vapors produced by electronic cigarettes and e-juices with flavorings induce toxicity, oxidative stress, and inflammatory response in lung epithelial cells and in mouse lung. PLoS One. 2015;10(2):e0116732.

4. Glynos C, Bibli SI, Katsaounou P, et al. Comparison of the effects of e-cigarette vapor with cigarette smoke on lung function and inflammation in mice. Am J Physiol Lung Cell Mol Physiol. 2018;315(5):L662-L672. doi:10.1152/ajplung.00389.2017

5. Masso-Silva JA, Moshensky A, Shin J, et al. Chronic E-Cigarette Aerosol Inhalation Alters the Immune State of the Lungs and Increases ACE2 Expression, Raising Concern for Altered Response and Susceptibility to SARS-CoV-2. Front Physiol. 2021;12:649604. doi:10.3389/fphys.2021.649604

6. Rankin GD, Wingfors $\mathrm{H}$, Uski $\mathrm{O}$, et al. The toxic potential of a fourth-generation E-cigarette on human lung cell lines and tissue explants. J Appl Toxicol. 2019;39(8):1143-1154. doi:10.1002/jat.3799

7. Pepper JK, MacMonegle AJ, Nonnemaker JM. Adolescents' Use of Basic, Intermediate, and Advanced Device Types for Vaping. Nicotine Tob Res. 2019;21(1):55-62. doi:10.1093/ntr/ntx279

8. Walley SC, Wilson KM, Winickoff JP, Groner J. A Public Health Crisis: Electronic Cigarettes, Vape, and JUUL. Pediatrics. 2019;143(6):e20182741. doi:10.1542/peds.2018-2741

9. Gravely S, Driezen P, Ouimet J, et al. Prevalence of awareness, ever-use and current use of nicotine vaping products (NVPs) among adult current smokers and ex-smokers in 14 
countries with differing regulations on sales and marketing of NVPs: cross-sectional findings from the ITC Project. Addiction. 2019;114(6):1060-1073. doi:10.1111/add.14558

10. Romijnders KA, Krüsemann EJ, Boesveldt S, Graaf K, Vries H, Talhout R. E-Liquid Flavor Preferences and Individual Factors Related to Vaping: A Survey among Dutch Never-Users, Smokers, Dual Users, and Exclusive Vapers. Int J Environ Res Public Health. 2019;16(23):4661. doi:10.3390/ijerph16234661

11. Blagev DP. No man is an island: e-cigarette, or vaping, associated lung injury in Europe. Eur Respir J. 2020 Feb 6;55(2):1902419. doi: 10.1183/13993003.02419-2019.

12. Besaratinia A, Tommasi S. Vaping epidemic: challenges and opportunities. Cancer Causes Control. 2020;31(7):663667. doi:10.1007/s10552-020-01307-y

13. Besaratinia A. COVID-19: a pandemic converged with global tobacco epidemic and widespread vaping-state of the evidence. Carcinogenesis. 2021;42(8):1009-1022. doi:10.1093/ carcin/bgab061

14. Gaga R, Pop TL. The vaping phenomenon - knowing the risks of consuming electronic cigarettes in teenagers. Pediatru Ro. 2020;59(3):18-21. doi:10.26416/Pedi.59.3.2020.3898.

15. Bracken-Clarke D, Kapoor D, Baird AM, Buchanan PJ, Gately K, Cuffe S, Finn SP. Vaping and lung cancer - A review of current data and recommendations. Lung Cancer. 2021
Mar;153:11-20. doi: 10.1016/j.lungcan.2020.12.030. Epub 2021 Jan 2. PMID: 33429159.

16. Tang MS, Wu XR, Lee HW, et al. Electronic-cigarette smoke induces lung adenocarcinoma and bladder urothelial hyperplasia in mice [published correction appears in Proc Natl Acad Sci U S A. 2019 Nov 5;116(45):22884]. Proc Natl Acad Sci U $S$ A. 2019;116(43):21727-21731. doi:10.1073/pnas. 1911321116

17. Klawinski D, Hanna I, Breslin NK, Katzenstein HM, Indelicato DJ. Vaping the Venom: Oral Cavity Cancer in a Young Adult With Extensive Electronic Cigarette Use. Pediatrics. 2021 May;147(5):e2020022301. doi: 10.1542/peds.2020-022301. PMID: 33926987.

18. Tang MS, Wu XR, Lee HW, et al. Electronic-cigarette smoke induces lung adenocarcinoma and bladder urothelial hyperplasia in mice [published correction appears in Proc Natl Acad Sci U S A. 2019 Nov 5;116(45):22884]. Proc Natl Acad Sci U $S$ A. 2019;116(43):21727-21731. doi:10.1073/pnas.1911321116

19. Ferrara P, Franceschini G, Corsello G, NamazovaBaranova L, Pop TL, Mestrovic J, et al. The Health Risks of Electronic Cigarettes Use in Adolescents. J Pediatrics. 2020; 219:286-287.e3. doi: 10.1016/j.jpeds.2020.01.009

20. Pettoello-Mantovani M, Campanozzi A, Maiuri L, Giardino I. Family-oriented and family-centered care in pediatrics. Ital J Pediatr. 2009;35(1):12. doi:10.1186/1824-7288-35-12 